\title{
The Schizophrenia Susceptibility Gene Dysbindin Regulates Dendritic Spine Dynamics
}

\author{
Jie-Min Jia, ${ }^{\star}$ Zhonghua Hu, ${ }^{\star}$ Jacob Nordman, ${ }^{\star}$ and $『$ Zheng Li \\ Unit on Synapse Development and Plasticity, National Institute of Mental Health, National Institutes of Health, Bethesda, Maryland 20892-3732
}

\begin{abstract}
Dysbindin is a schizophrenia susceptibility gene required for the development of dendritic spines. The expression of dysbindin proteins is decreased in the brains of schizophrenia patients, and neurons in mice carrying a deletion in the dysbindin gene have fewer dendritic spines. Hence, dysbindin might contribute to the spine pathology of schizophrenia, which manifests as a decrease in the number of dendritic spines. The development of dendritic spines is a dynamic process involving formation, retraction, and transformation of dendritic protrusions. It has yet to be determined whether dysbindin regulates the dynamics of dendritic protrusions. Here we address this question using time-lapse imaging in hippocampal neurons. Our results show that dysbindin is required to stabilize dendritic protrusions. In dysbindin-null neurons, dendritic protrusions are hyperactive in formation, retraction, and conversion between different types of protrusions. We further show that CaMKII $\alpha$ is required for the stabilization of mushroom/thin spines, and that the hyperactivity of dendritic protrusions in dysbindin-null neurons is attributed in part to decreased CaMKII $\alpha$ activity resulting from increased inhibition of CaMKII $\alpha$ by Abil. These findings elucidate the function of dysbindin in the dynamic morphogenesis of dendritic protrusions, and reveal the essential roles of dysbindin and CaMKII $\alpha$ in the stabilization of dendritic protrusions during neuronal development.
\end{abstract}

Key words: CaMKIIa; dendritic spine; dynamics; dysbindin; hippocampus; schizophrenia

\section{Introduction}

Dysbindin is a coiled-coil domain containing protein, initially discovered as a dystrophin-binding protein and later found to be one of eight subunits of biogenesis of lysosome-related organelles complex 1 (BLOC-1; Benson et al., 2001; Li et al., 2003). Singlenucleotide polymorphisms of the dysbindin gene (Dtnbp1) have been associated with higher risk for schizophrenia, and the postmortem brains of schizophrenia patients consistently exhibit low levels of dysbindin proteins and mRNAs (Straub et al., 2002; Talbot et al., 2004; Weickert et al., 2008). Mice carrying a deletion mutation in Dtnbp1 (sdy mice, express no dysbindin proteins) have more of the cell-surface dopamine $\mathrm{D} 2$ receptors, which have long been targeted in the treatment of schizophrenia (Howes and Kapur, 2009; Ji et al., 2009).

Proper synaptic connections between neurons are critical for brain function. In schizophrenia patients, however, MRI studies show that functional connectivity between brain regions is impaired, and there are fewer dendritic spines in their prefrontal cortex and hippocampus (Garey et al., 1998; Glantz and Lewis, 2000; Kolluri et al., 2005; Kolomeets et al., 2005; Lynall et al., 2010). Therefore, it is

\footnotetext{
Received Jan. 15, 2014; revised Aug. 10, 2014; accepted Aug. 31, 2014.

Author contributions: J.-M.J., Z.H., and Z.L. designed research; J.-M.J., Z.H., and J.N. performed research; J.-M.J. and J.N. analyzed data; J.-M.J. and Z.L. wrote the paper.

This work was supported by the NIMH Intramural Program. We thank Dr Elizabeth J. Sherman (NIMH/NIH) for editing the paper.

*J.-M.J., Z.H., and J.N. contributed equally to this work.

The authors declare no competing financial interests.

Correspondence should be addressed to Dr Zheng Li, National Institutes of Health, 35 Convent Drive, Room 2C1010, Bethesda, MD 20892. E-mail: lizheng2@mail.nih.gov.

DOI:10.1523/JNEUROSCI.0184-14.2014

Copyright $\odot 2014$ the authors $\quad 0270-6474 / 14 / 3413725-12 \$ 15.00 / 0$
}

thought that neuronal dysconnectivity underlies anomalous brain function associated with schizophrenia. Our recent study suggests that dysbindin contribute to the establishment of neuronal connectivity by regulating the development of dendritic protrusions (Jia et al., 2013), including dendritic spines (tiny dendritic protrusions where excitatory synapses are formed) and filopodia (long, thin protrusions that predominant in young neurons; Wenzel and Bogolepov, 1976; Li and Sheng, 2003). Hippocampal neurons of $s d y$ mice have fewer dendritic spines and more filopodia, and synaptic connectivity within the entorhinal cortex-hippocampus circuit is miswired (Jia et al., 2013).

The development of dendritic protrusions is a dynamic process involving addition of new protrusions, retraction of existing ones, and conversion between one type of protrusions (stubby spines, mushroom spines, thin spines, filopodia) to another (Parnass et al., 2000). These dynamic events in the morphogenesis of dendritic protrusions facilitate not only formation and maturation, but also plasticity of synaptic connections, which are needed to establish and refine neural circuits. It remains to be determined, however, whether dysbindin regulates the dynamic changes of dendritic protrusions during development.

Here by using time-lapse imaging, we found that hippocampal neurons of $s d y$ mice are hyperactive in addition, retraction and transformation of dendritic protrusions. Investigating mechanisms might account for this hyperactivity, we found that the calcium/ calmodulin-dependent protein kinase CaMKII $\alpha$ is required to stabilize dendritic protrusions, and that decreased CaMKII $\alpha$ activity in $s d y$ mice contributes to the hyperactivity of dendritic protrusions. We also demonstrated that diminished CaMKII $\alpha$ activity is caused by enhanced interaction of CaMKII $\alpha$ and Abil, a protein forming complexes with dysbindin. This study reveals a key mechanism by 
A

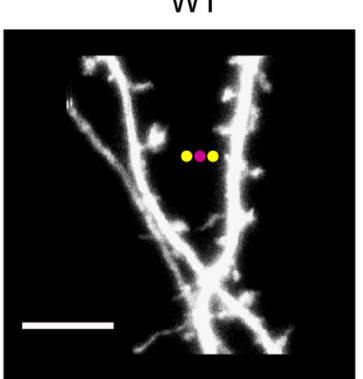

C

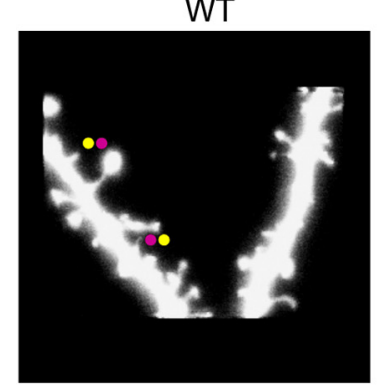

E

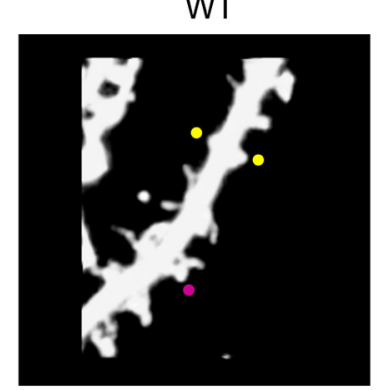

Sdy

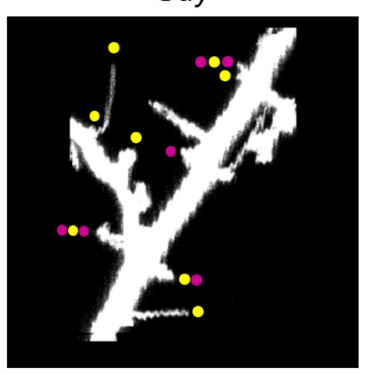

Sdy

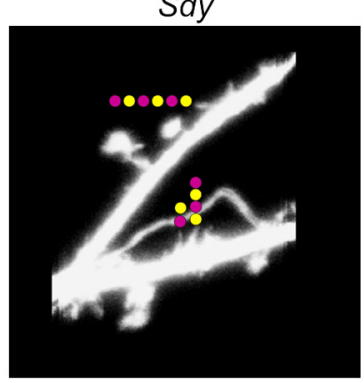

Sdy

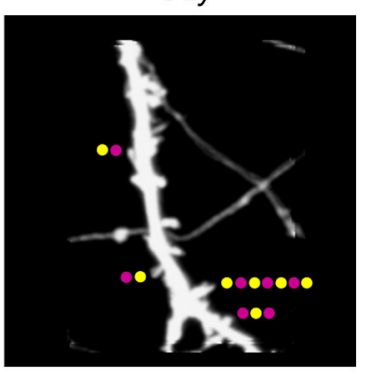

. WT

¿Sdy

B

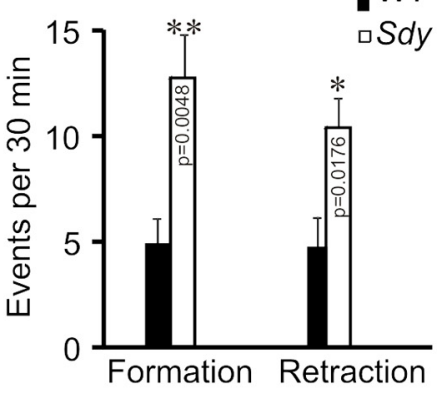

D

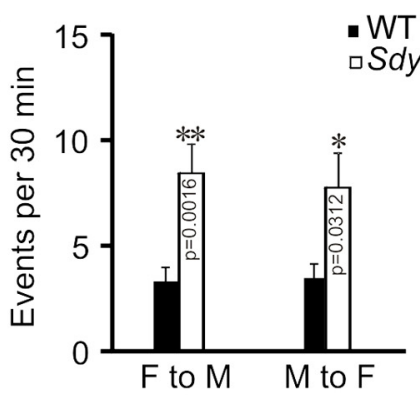

F

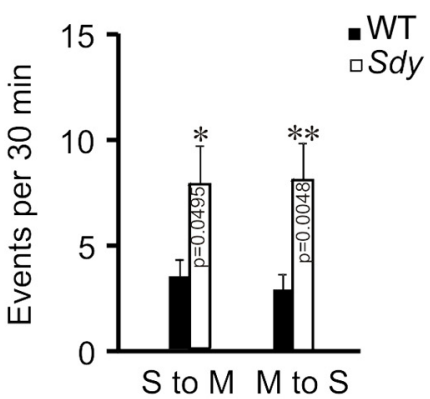

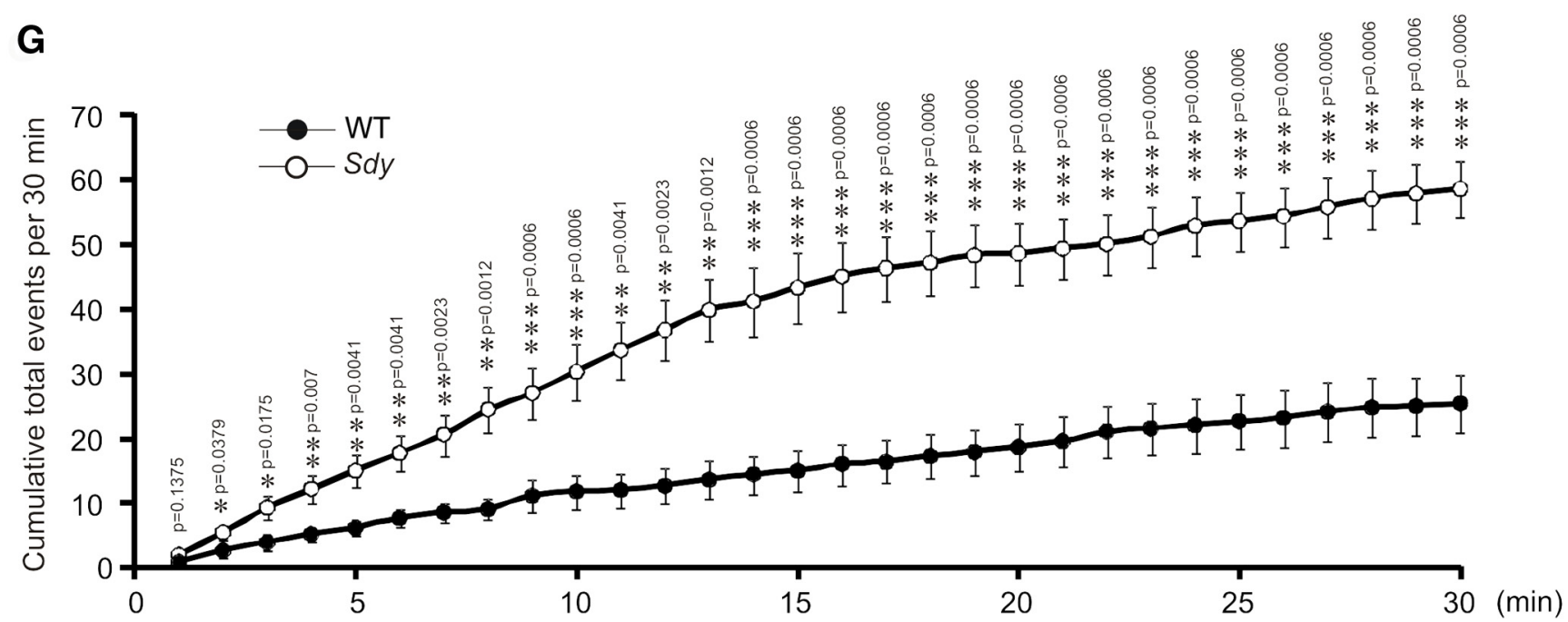

Figure 1. The dynamics of dendritic protrusions are increased in sdy neurons. Hippocampal neurons from wild-type or sdy mice were transfected at 14 DIV with the Venus construct and imaged every minute for $30 \mathrm{~min}$ at 17 DIV. $\boldsymbol{A}, \boldsymbol{C}, \boldsymbol{E}$, Representative images superimposed from those taken at 4 adjacent time points during the 30 min live-imaging period. In $\boldsymbol{A}$, red dots represent protrusion retraction, yellow dots indicate protrusion addition; in $\boldsymbol{C}$, red dots represent the transformation from mushroom/thin spines to filopodia, yellow dots indicate the transformation in the opposite direction; in $\boldsymbol{E}$, red dots represent the conversion from mushroom/thin to stubby spines, yellow dots indicate the conversion in the opposite direction. $\boldsymbol{B}, \boldsymbol{D}, \boldsymbol{F}, \mathrm{Quantification}$ of $\boldsymbol{A}, \boldsymbol{C}, \boldsymbol{E}$. $\boldsymbol{G}$, Cumulative frequency plot of total dynamic events occurring during the 30 min imaging period. Scale bar, $5 \mu \mathrm{m}$. Data are presented as mean \pm SEM; ${ }^{*} p<0.05,{ }^{* *} p<0.01,{ }^{* *} p<0.001$. 


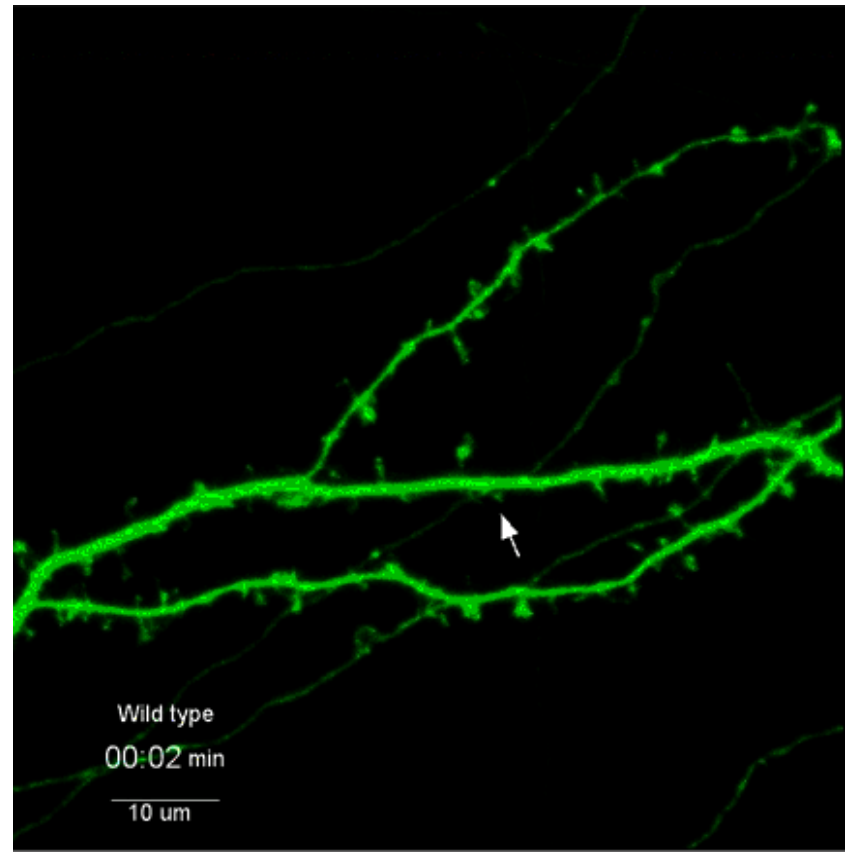

Movie 1. Dynamics of dendrite protrusions in wild-type neurons. Hippocampal neurons from wild-type mice were transfected with the Venus construct at 14 DIV. This movie shows confocal images of transfected dendrites taken every minute for 30 min at 17 DIV.

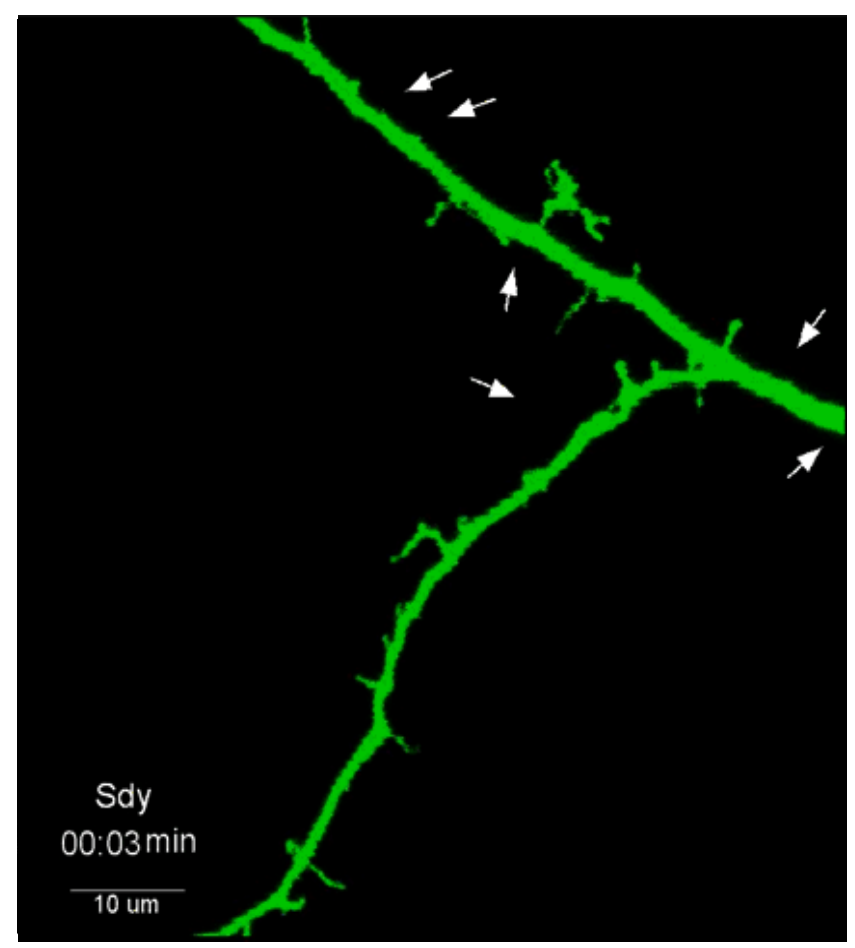

Movie 2. Dynamics of dendrite protrusions in sdy neurons. Hippocampal neurons from sdy mice were transfected with the Venus construct at 14 DIV. This movie shows confocal images of transfected dendrites taken every minute for $30 \mathrm{~min}$ at 17 DIV.

which dysbindin regulates the development of dendritic spines and an essential role of CaMKII $\alpha$ in the dynamics of dendritic protrusions.

\section{Materials and Methods}

Animals, plasmids, and reagents. All animal procedures followed the NIH Guidelines Using Animals in Intramural Research, and were approved by the
National Institute of Mental Health Animal Care and Use Committee. Four mice of the same sex were housed in one cage in a room with a $12 \mathrm{~h}$ light/dark cycle. $S d y$ mice (backcrossed with the C57BL/6J mice for $>10$ generations) were purchased from The Jackson Laboratory. Littermates of wild-type and $s d y$ mice (of either sex) were used in quantitative reverse-transcription (RT)PCR and immunoblotting analyses. SiRNAs targeting mRNAs encoding dysbindin and scrambled oligonucleotides were inserted into the pSuper plasmid. The sequences of dysbindin siRNAs and scrambled oligonucleotides are as follows: GCACCACTCTACCCTATTA (dys-siRNA1), CGGCCTTGGTCACATTAAA (dys-siRNA2), GACGTTAAGCGACAAGTCA (dys-siRNA3), and GACGTGAACGGATAACACT (scrambled oligonucleotides). The CaMKII siRNA was purchased from Thermo Fisher Scientific (catalog \#A-059173-14). Antibodies against the following proteins were obtained commercially: phosphorylated CaMKII $\alpha$ (1: 500; catalog \#3361, Cell Signaling Technology), CaMKII $\alpha$ (1:1000; catalog \#13-7300, Invitrogen), Abil (catalog \#D147-3, MBL), actin (1:10,000; catalog \#A4700, SigmaAldrich), and IgG (H+L; HRP-conjugated; Bio-Rad). A rabbit polyclonal anti-dysbindin antibody was raised (Covance) against the $\mathrm{C}$-terminal region of rat dysbindin (amino acids 202-350) and affinity-purified before use. Immunoblots were analyzed using ImageJ software.

Neuronal culture and transfection. Cultures of hippocampal neurons were prepared from embryonic day (E)18-19 rat or mouse embryos (of either sex) as previously described (Jia et al., 2013) and grown in neurobasal medium (Invitrogen) supplemented with 2\% B27 (Invitrogen), 1\% glutamax (Invitrogen). Hippocampal neurons were seeded at a density of 300 cells/ $\mathrm{mm}^{2}$. Neurons were transfected with Lipofectamine 2000 (Invitorgen, for plasmids) or DharmaFECT (Thermo Scientific, catalog \#T-2010-01, for siRNA oligonucleotides)

Time-lapse imaging and analysis of dendritic protrusions. Coverslips seeded with hippocampal neurons were placed in a chamber perfused with artificial CSF (ACSF), consisting of the following (in $\mathrm{mm}$ ): $124 \mathrm{NaCl}, 26 \mathrm{NaHCO}_{3}$, $1.25 \mathrm{NaH}_{2} \mathrm{PO}_{4}, 2.5 \mathrm{CaCl}_{2} 1.3 \mathrm{MgSO}_{4}$, and 10 D-glucose. ACSF was maintained at a temperature of $30^{\circ} \mathrm{C}$. We used an Olympus FV1000 confocal microscope with a $60 \times$ (NA 1.35) objective for time-lapse imaging and a Zeiss LSM510 confocal microscope $(63 \times$ objective, NA1.4) for imaging cells fixed in PBS containing 4\% formaldehyde and 4\% sucrose. Images were collapsed into $2 \mathrm{D}$ projections and analyzed with the MetaMorph software (Molecular Devices) for the number and dimension of dendritic protrusions. Images taken from adjacent time points were compared with track the shape change, appearance, or disappearance of dendritic protrusions. We divided all dendritic spines ( $0.5-6 \mu \mathrm{m}$ in length) into two subgroups: mushroom/thin spines (with an enlarged head and constricted neck) and stubby spines (without constricted necks). Long, pointed dendritic protrusions that are 3-6 $\mu \mathrm{m}$ long were categorized as filopodia. Formation of protrusions was defined as generation of new spines or filopodia, retraction was disappearance of pre-existing spines or filopodia, and conversion was the transformation of spines and filopodia into other types of protrusions. These dynamic events were analyzed by comparing consecutive images taken every minute during a $30 \mathrm{~min}$ period.

$R T-P C R$. At 3 weeks of age, the hippocampus of $s d y$ mice and their wildtype littermates (of either sex) were lysed in Trizol (Invitrogen). mRNAs were extracted and transcribed into cDNAs with the oligo (dT) 20 primer. The following primers (CaMKII $\alpha$ : $5^{\prime}$ primer AAGCACCCATGGATCTCGCACC, 3' primer GGCTTCGATCAGCTGCTCTGTCAC; dysbindin: 5' primer CAGGACGTGGAGTCCTTGAT, 3' primer GCATGGGCCTGTTTATGTCT; actin: $5^{\prime}$ primer GCTCCTCCTGAGCGCAAGTACTC, 3' primer CTCATCGTACTCCTGCTTGCTG) were used for real-time PCR.

Western blotting and antibodies. At 2-3 weeks of age, the hippocampus of $s d y$ mice and their wild-type littermates (of either sex) was lysed in RIPA buffer (20 mм HEPES, 150 mm NaCl, 5 mм EDTA, 1\% Triton X-100, 0.1\% SDS, protease inhibitor cocktail). The cell lysate was electrophoresed through SDS-PAGE gels, transferred to PVDF membranes, and subjected to immunoblotting with antibodies against phosphorylated-CaMKII $\alpha$ (1:500; catalog \#3361, Cell Signaling Technology), CaMKII $\alpha$ (1:1000; catalog \#137300, Invitrogen) and actin (1:10,000; catalog \#A4700, Sigma-Aldrich). IgG(H+L)-HRP-conjugated secondary antibodies were obtained from BioRad. Immunoblots were quantified using ImageJ software.

Immunocytochemistry. Hippocampal neurons grown on coverslips were fixed with PBS containing 4\% formaldehyde and $4 \%$ sucrose for $12 \mathrm{~min}$. 
A
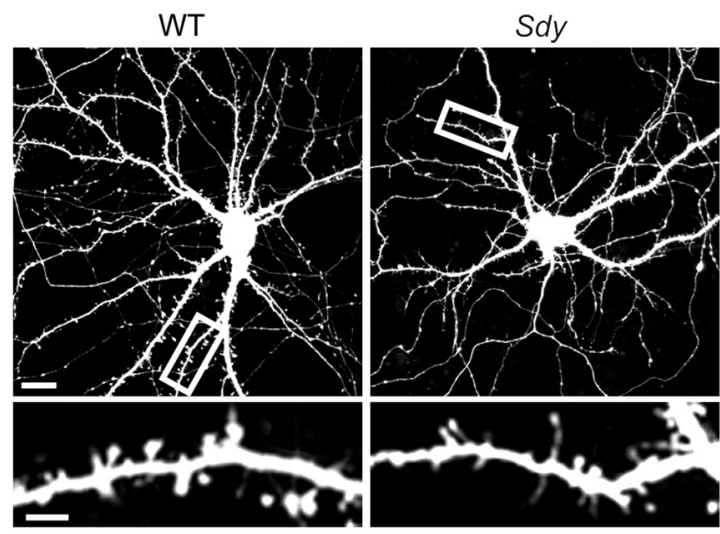

C

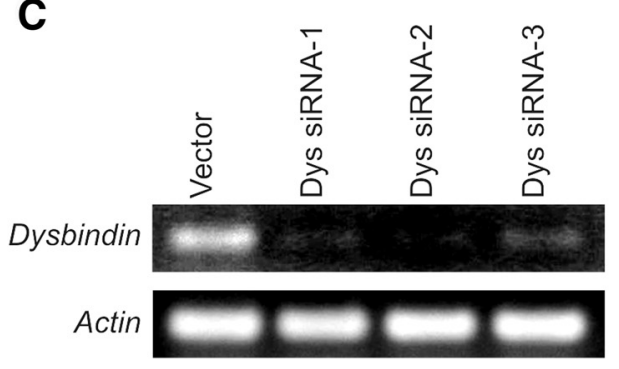

D

$\mathbf{F}$

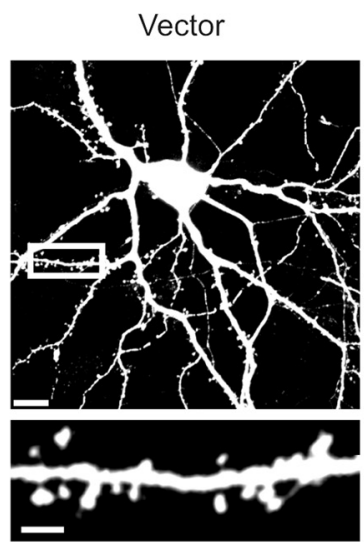

Dys-siRNA-2

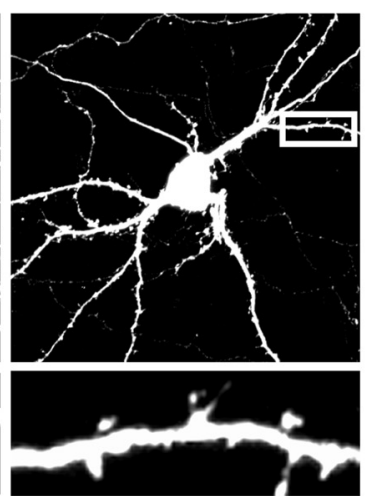

Dys-siRNA-2+mDys

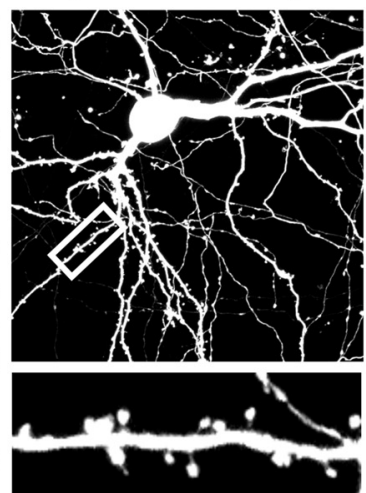

E

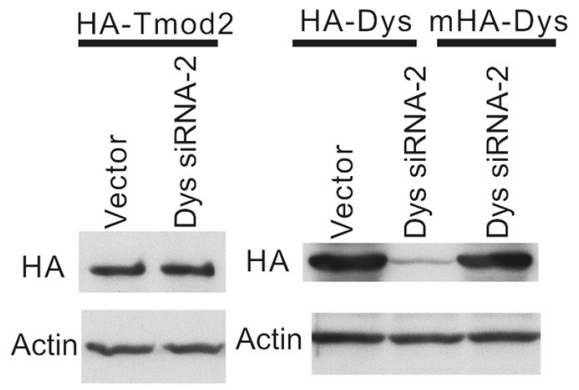

Figure 2. The change to dendritic protrusion density in sdy and dysbindin knockdown neurons. Cultured hippocampal neurons were prepared from sdy mice or their wild-type littermates $(\boldsymbol{A}, \boldsymbol{B})$ or rats $(\boldsymbol{F}, \boldsymbol{G})$, and transfected with the Venus construct alone $(\boldsymbol{A}, \boldsymbol{B})$ or along with lentivirus expressing dysbindin siRNA and siRNA-resistant dysbindin (mDys) at 14 DIV. $\boldsymbol{A}, \boldsymbol{F}$, Representative images of neurons and dendrites. Scale bars: neurons, $20 \mu \mathrm{m}$; dendrites, $5 \mu \mathrm{m}$. $\boldsymbol{B}, \mathbf{G}$, Quantification for $\boldsymbol{A}$ and $\boldsymbol{F} ; n=15$ cells in each group; data are presented as mean \pm SEM; ${ }^{*} p<0.05$, ${ }^{* *} p<0.01$. $C, E$, Cultured wild-type cortical neurons were infected with lentivirus expressing EGFP alone or along with siRNAs targeting dysbindin mRNAs at 5 DIV and harvested for RT-PCR and immunoblotting analysis for endogenous dysbindin mRNAs and proteins at 2 weeks after infection. D, HEK 293 cells were transfected with plasmids expressing HA-tagged dysbindin, tropomodulin 2- (Tmod2, containing no dysbindin siRNA-2 binding sites) or siRNA-resistant dysbindin along with the dysbindin siRNA construct, and harvested at $2 \mathrm{~d}$ after transfection for immunoblotting.

After rinse, cells were incubated with the anti-CaMKII $\alpha$ or MAP2 (1:200; Sigma-Aldrich, catalog \#M9942) antibody overnight at $4^{\circ} \mathrm{C}$, and then with AlexaFluor 555 secondary antibodies for $2 \mathrm{~h}$ at room temperature.

Immunoprecipitation. The P2 (crude synaptosomal) fraction was prepared as described previously (Lau et al., 1996). Briefly, hippocampal tissue from mice of either sex was homogenized in ice-cold homogenization buffer supplemented with protease and phosphatase inhibitors (Roche) using a glass dounce homogenizer. Nuclear fraction was removed via centrifugation $\left(800 \times g\right.$ for $10 \mathrm{~min}$ at $\left.4^{\circ} \mathrm{C}\right)$. The $\mathrm{P} 2$ fraction was isolated by centrifugation at $10,000 \times g$ for $15 \mathrm{~min}$ at $4^{\circ} \mathrm{C}$, and solubilized in a nondenaturing lysis buffer (1\% Triton X-100, $137 \mathrm{~mm} \mathrm{NaCl}, 2$ mm EDTA, $20 \mathrm{~mm}$ Tris $\mathrm{HCl}$, pH 8, supplemented with protease and phosphatase inhibitors) at $4^{\circ} \mathrm{C}$ for $1 \mathrm{~h}$. Synaptosomal proteins $(500 \mu \mathrm{g})$ were incubated with Protein G Sepharose Fast Flow 4 beads (GE) conjugated to anti-Abil monoclonal Abs (catalog
\#D147-3, MBL) or purified rabbit IgG Ab as an IP control. After wash with the lysis buffer, bound proteins were eluted by boiling and separated by gel electrophoresis on $12 \%$ acrylamide gels for immunoblotting. Quantification of immunoblotting was based on three independent experiments.

\section{Results}

Dysbindin regulates the dynamics of dendritic protrusions To determine whether dysbindin regulates the dynamics of synaptic connections during development, we used time-lapse imaging to examine dendritic protrusions (including mushroom spines, thin spines, stubby spines, and filopodia) in cultured hippocampal neurons taken from $s d y$ and wild-type mice. Because of the limited spatial resolution of confocal microscopy, we classi- 
A
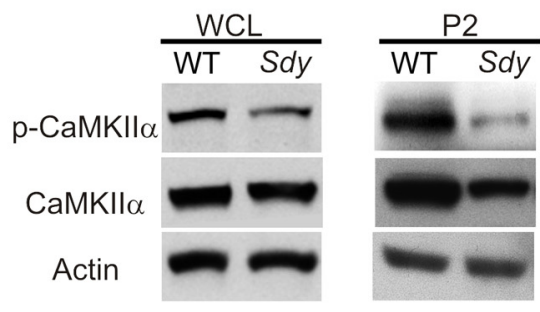

C
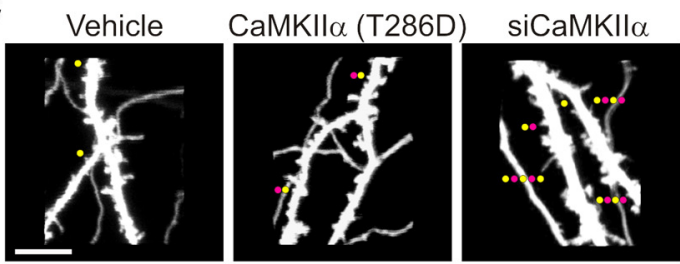

E
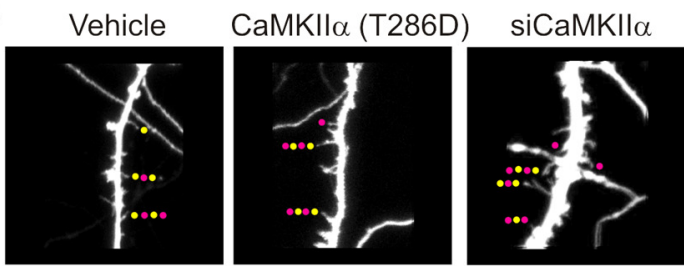

G

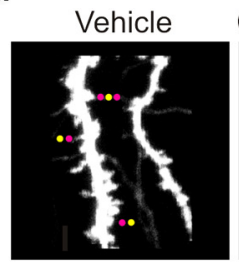

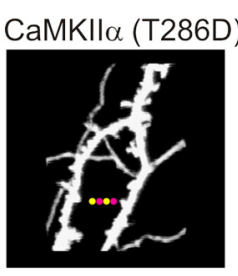

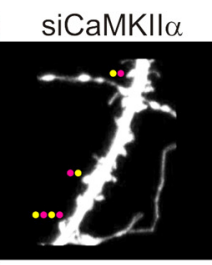

B

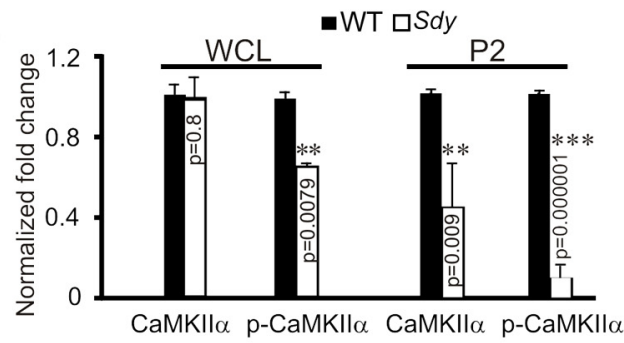

D

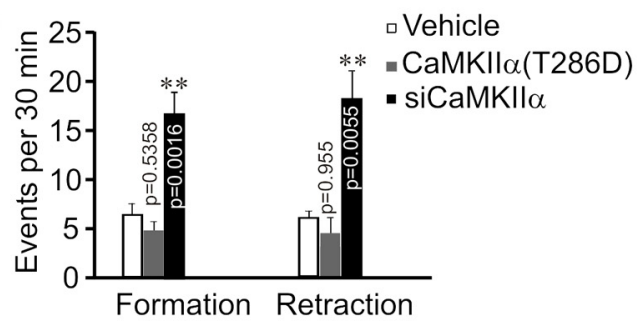

$\mathbf{F}$

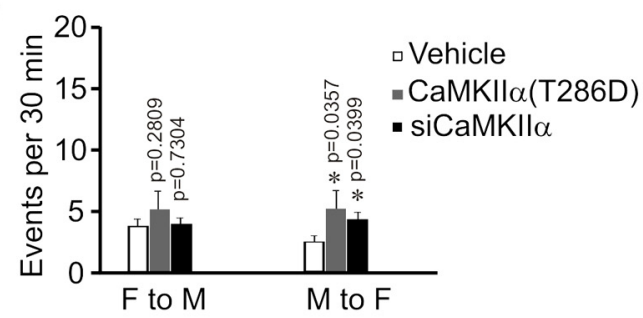

H

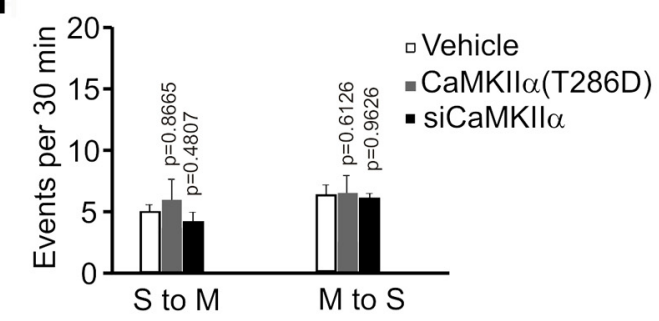

I

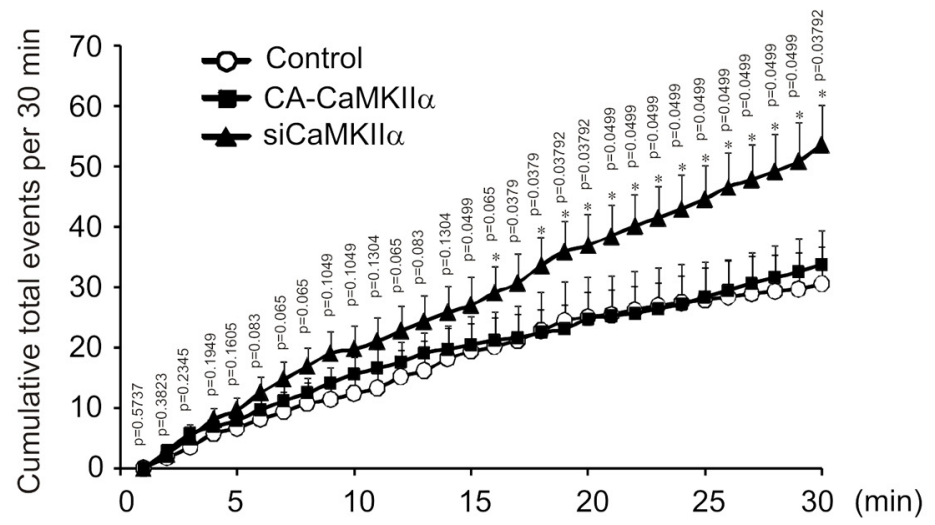

Figure 3. CaMKII $\alpha$ is required for the stabilization of dendritic protrusions. $A, B$, Hippocampi of 2-to 3-week-old sdy mice and their wild-type littermates were removed for analyses of CaMKIl $\alpha$ and CaMKIl $\alpha$ phosphorylated at Thr286 in whole-cell lysates (WCL) and the P2 fraction. $\mathbf{C}-I$, Hippocampal neurons were transfected at 14 DIV with the Venus construct along with the CA-CaMKII $\alpha$ or the CaMKII $\alpha$ siRNA oligonucleotides, and imaged every minute for 30 min at 17 DIV.A, Representativeblots. $B$, Quantification for $A ; n=4$ experiments. $C, E, G$, Representative images superimposed from thosetaken at 4 contiguous time points during the $30 \mathrm{~min}$ live-imaging period. Red dots represent protrusion retraction ( $(\boldsymbol{C}$, the transformation from mushroom/thin spines to filopodia $(\boldsymbol{E})$, and the conversion from mushroom/thin to stubby spines $(\boldsymbol{G})$; yellow dots indicate the protrusion addition $(\boldsymbol{C})$, the transformation from filopodia to mushroom/thin spines $(\boldsymbol{E})$, and the conversion from stubby to mushroom/thin spines $(\boldsymbol{G})$. $\boldsymbol{D}, \boldsymbol{F}, \boldsymbol{H}$, Quantification of $C, E, G$.I, Cumulative frequency plot for the total number of all types of dynamic events taking place during the 30 min period. Scale bar, $5 \mu \mathrm{m}$. Data are presented as mean \pm SEM; ${ }^{*} p<0.05$, ${ }^{* *} p<0.01$.

fied mushroom and thin spines into one group (mushroom/thin spines). Neurons were transfected at $14 \mathrm{~d}$ in vitro (DIV) with a construct expressing Venus (a mutant of yellow fluorescent protein) and then imaged at 16-21 DIV, when dendritic protrusions undergo dynamic formation, retraction, and transformation (Parnass et al., 2000; Nagai et al., 2002). We imaged the same dendritic branch (secondary and associated tertiary dendrites) every minute for $30 \mathrm{~min}$, and analyzed dynamic events taking place 
during the imaging period, including formation of new protrusions, retraction of existing protrusions, and conversion between mushroom/thin and stubby spines, between mushroom/thin spines and filopodia, and between stubby spines and filopodia. We found that in 16-21 DIV neurons, the frequency of conversion between stubby spines and filopodia was very low ( $<1$ event in $30 \mathrm{~min}$ ), and therefore focused our analysis on other types of dynamic changes. All analyzed activities were more dynamic in $s d y$ than in wildtype neurons (Fig. 1A-F; Movies 1, 2). During the imaging period, consequently, protrusions on $s d y$ neurons underwent more total dynamic changes than those on wild-type neurons (Fig. 1G). These results indicate that the loss of dysbindin leads to an enhancement in the dynamics of dendritic protrusions, thereby reducing the stability of synaptic connections.

This hyperactivity in the morphogenesis of dendritic protrusions might further result in changing their overall numbers. To assess protrusion number, we transfected hippocampal neurons from $s d y$ or wild-type mice with the Venus construct at 14 DIV, and fixed them at 17 DIV. Compared with wild-type neurons, $s d y$ neurons had more filopodia and fewer mushroom/thin spines (Fig. $2 A, B$ ). The changes in filopodia and mushroom/thin spines can result from imbalanced formation and retraction of protrusions. Indeed, we noticed that in $s d y$ neurons although the total amounts of formation and retraction for all three types of protrusions (mushroom/thin spines, stubby spines and filopodia) were comparable, newly added mushroom/thin spines outnumbered retracted ones (formation $1.94 \pm 0.45$ vs retraction $2.27 \pm 0.57)$, whereas more filopodia were added than retracted (formation $2.55 \pm 0.49$ vs retraction $1.32 \pm 0.37$ ) during the 30 min imaging period. In wildtype neurons, however, all three types of protrusions undergo balanced formation and retraction during the $30 \mathrm{~min}$ imaging period.

To test whether this change in protrusion number is due to cellautonomous effects of dysbindin, we generated constructs expressing siRNAs against dysbindin and tested their specificity and efficacy against both endogenous and overexpressed dysbindin (Fig. 2C-E). The dys-siRNA2 (one of the effective and specific siRNAs) and the Venus construct were cotransfected into cultured hippocampal neurons (14 DIV). Neurons transfected with the dys-siRNA construct had fewer mushroom/thin spines and more filopodia than control cells (Fig. $2 F, G$ ). These effects, however, were abolished when the dys-siRNA was cotransfected with a construct expressing dysbindin harboring silent mutations in the siRNA binding region (thereby resistant to dys-siRNA; Fig. 2E-G). Because of our low transfection efficiency $(<0.05 \%)$, the changes to dys-siRNA-

A

B

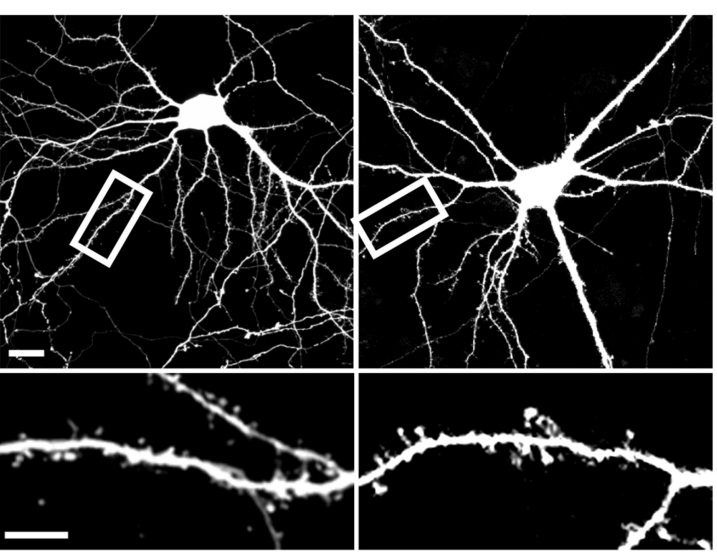
CaMKII $\alpha(T 286 \mathrm{D})$
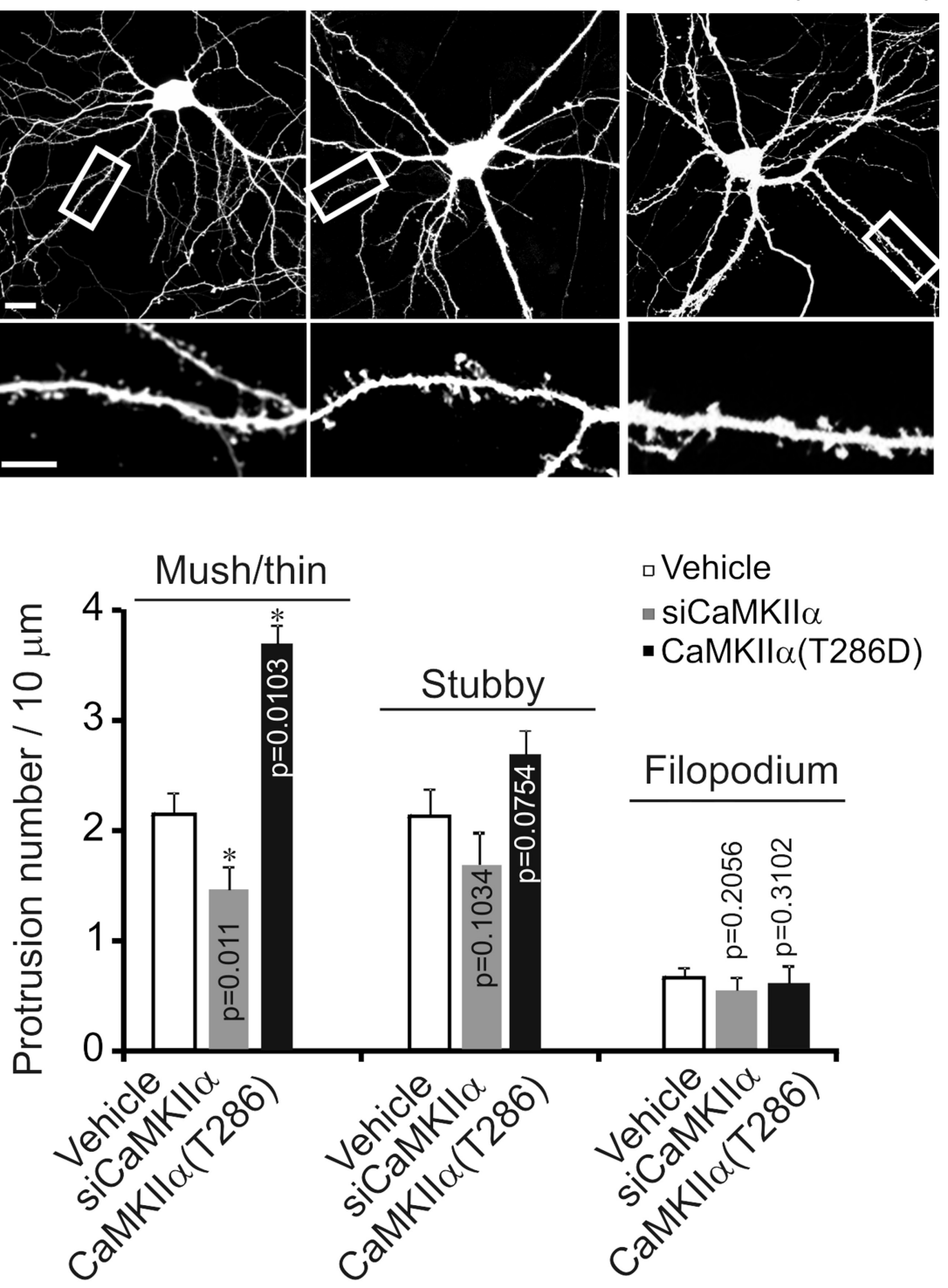

Figure 4. CaMKII $\alpha$ controls the number of mushroom/thin spines. Cultured hippocampal neurons from rats were transfected at 4 DIV with indicated plasmids. $\boldsymbol{A}$, Representative images of neurons (top) and dendrites (bottom). $\boldsymbol{B}$, Quantification for $A, n=15$ neurons for each group. Data are presented as mean \pm SEM; * $p<0.05$. Scale bars: neurons, $20 \mu \mathrm{m}$; dendrites, $5 \mu \mathrm{m}$.

transfected neurons are likely induced by cell-autonomous effects of dysbindin knockdown.

Together, these results indicate that dysbindin regulates the dynamics and composition of dendritic protrusions.

\section{CaMKII $\alpha$ is required to stabilize dendritic protrusions}

Having found that dysbindin regulates the dynamics of dendritic protrusions, we went on to investigate the underlying mechanism. Because CaMKII activity is required for experiencedependent stabilization of dendritic spines, and the expression of CaMKII is decreased in the prefrontal cortex of $s d y$ mice (Wilbrecht et al., 2010; Papaleo et al., 2012), we tested whether CaMKII contributes to the regulation of dendritic protrusions by dysbindin. We first examined whether CaMKII $\alpha$ expression is also changed in the hippocampus of $s d y$ mice. We prepared whole-cell lysates from the hippocampus of $s d y$ mice and their wild-type littermates at the age of 2-3 weeks. Analyzing by immunoblotting, we found that in $s d y$ mice although the protein 
A
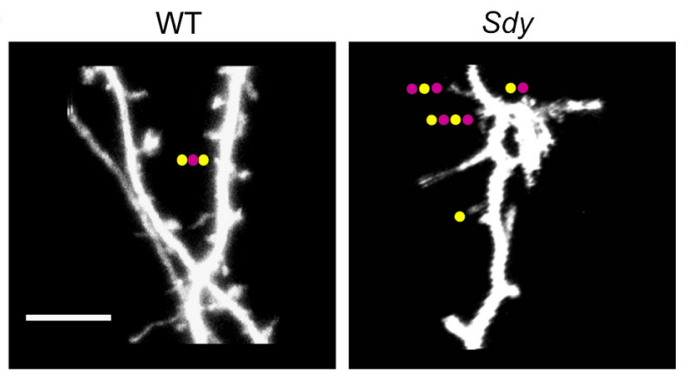

$S d y+$ CaMKII $\alpha(T 286 D)$

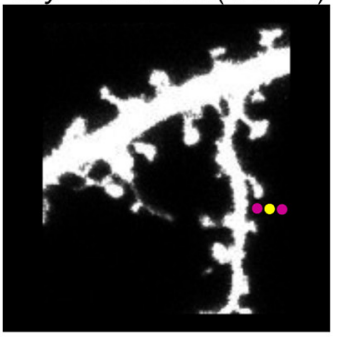

C
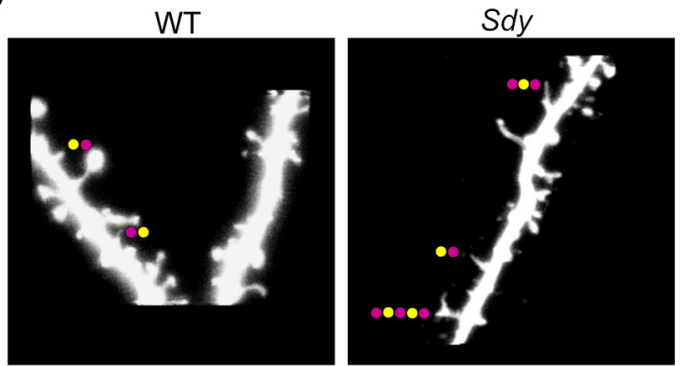

$S d y+\operatorname{CaMKIl} \alpha(T 286 \mathrm{D})$

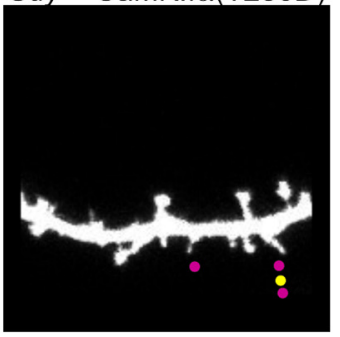

E

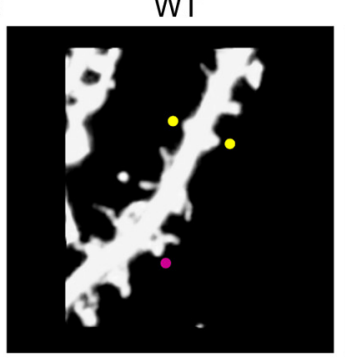

$S d y$

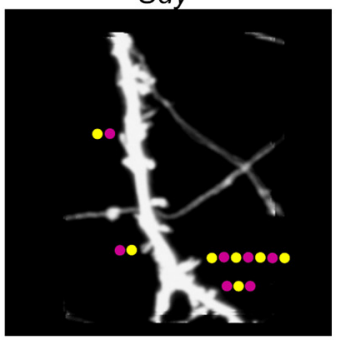

Sdy + CaMKII $\alpha($ T286D)

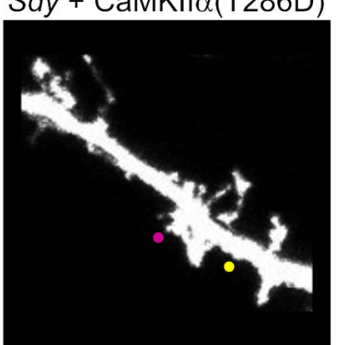

B

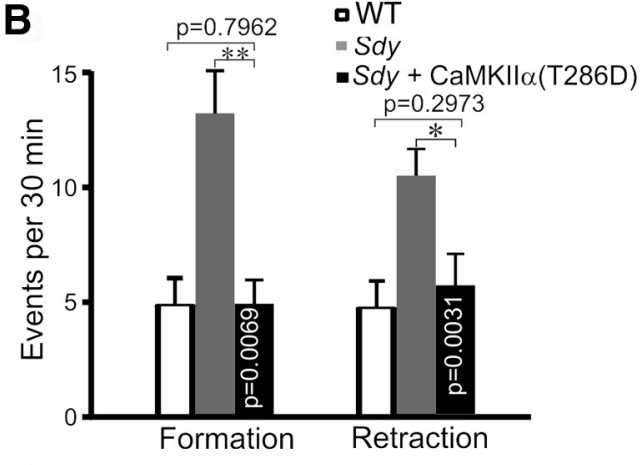

D

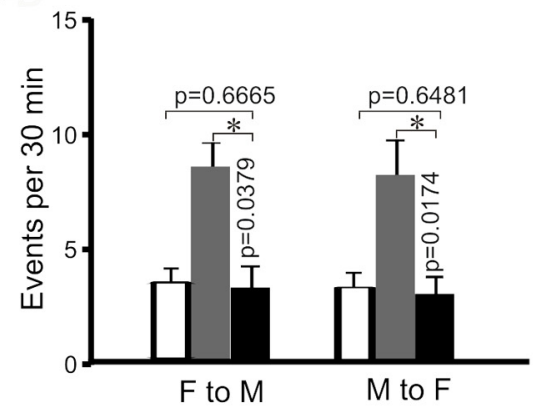

$\mathbf{F}$

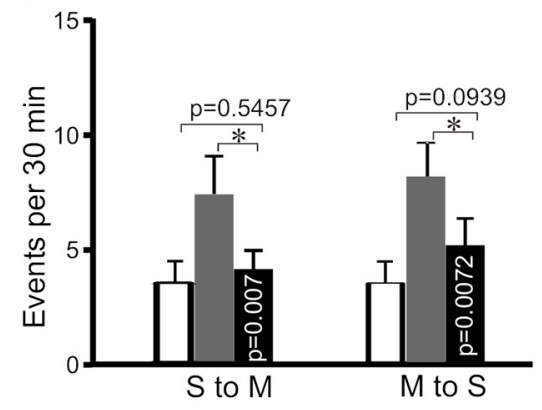

G

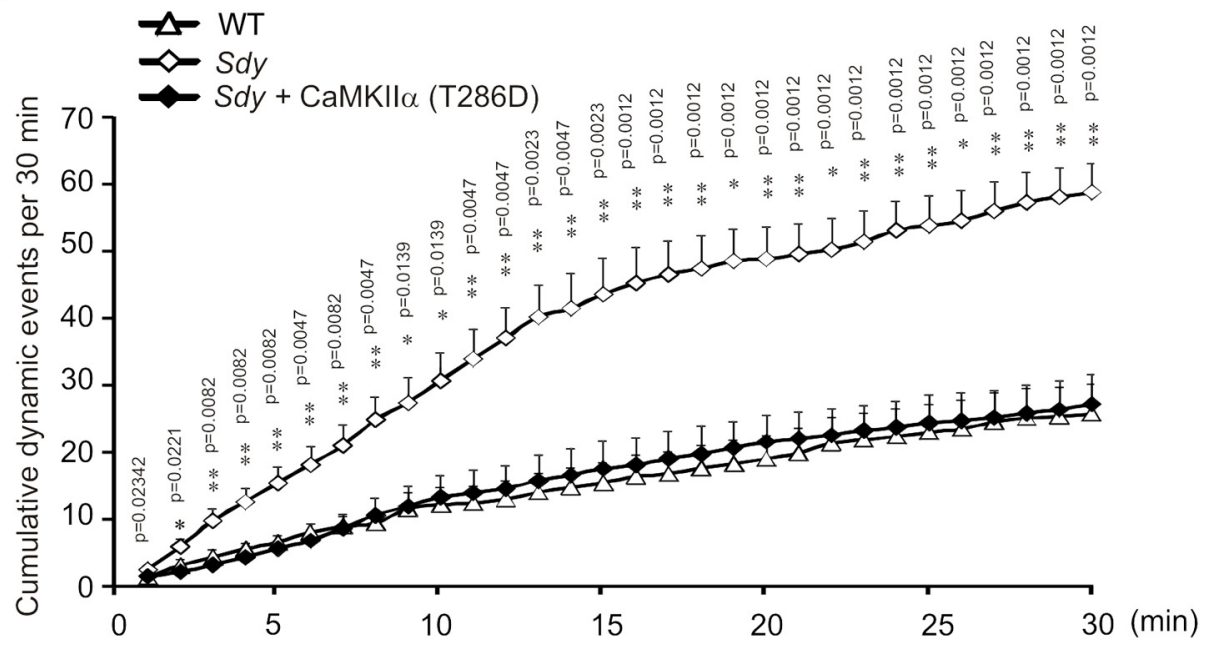

Figure 5. CaMKII $\alpha(\mathrm{T} 286 \mathrm{D})$ corrects the hyperactivity of dendritic protrusions in sdy neurons. Hippocampal neurons from wild-type or sdy mice were transfected at $14 \mathrm{DIV}$ with the Venus construct alone or along with the CaMKII $\alpha$ (T286D) construct, and imaged every minute for $30 \mathrm{~min}$ at 17 DIV. A, C, E, Representative images superimposed from those taken at four contiguous time points during the $30 \mathrm{~min}$ live-imaging period. Red dots represent protrusion retraction $(\boldsymbol{A})$, the transformation from mushroom/thin spines to filopodia $(\boldsymbol{C})$, the conversion from mushroom/thin to stubby spines $(\boldsymbol{E})$; yellow dots indicate protrusion addition $(\boldsymbol{A})$, the transformation from filopodia to mushroom/thin spines $(\boldsymbol{C})$, the conversion from stubby to mushroom/thin spines $(\boldsymbol{E})$. $\boldsymbol{B}, \boldsymbol{D}, \boldsymbol{F}$, Quantification of $A, C, E$. G, Cumulative frequency plot for the total number of all types of dynamic events taking place during the 30 min period. Scale bar, $5 \mu \mathrm{m}$. Data are presented as mean \pm SEM; ${ }^{*} p<0.05,{ }^{* *} p<0.01$. 
A

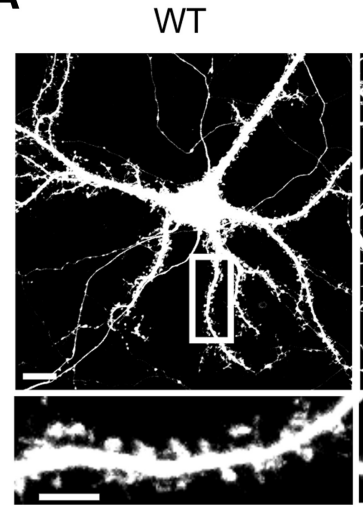

Sdy

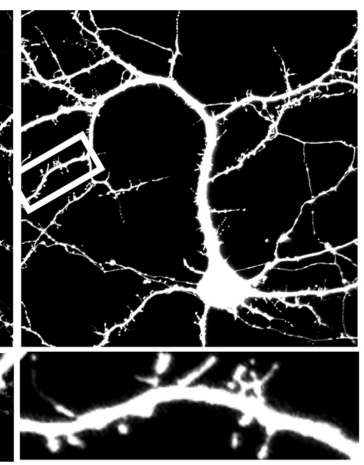

Sdy

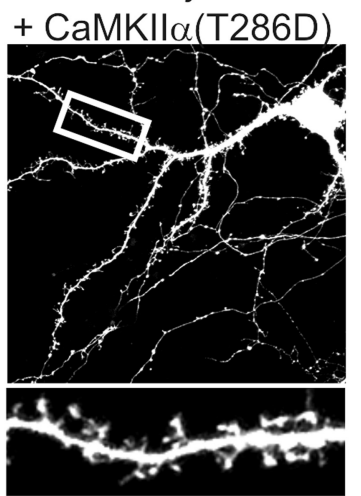

B

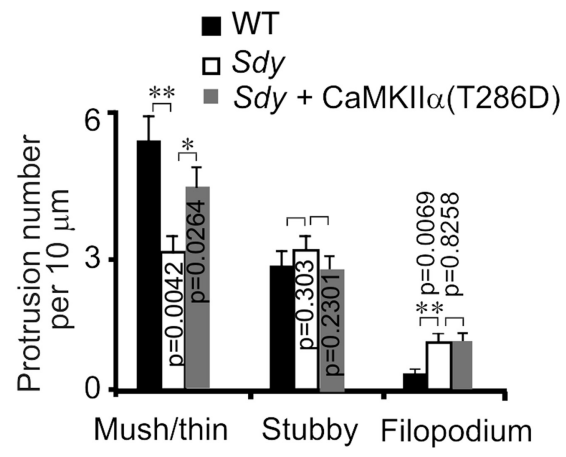

Figure 6. CaMKII $\alpha$ restores spine density in sdy neurons. Cultured hippocampal neurons from sdy or wild-type mice were transfected with the Venus construct alone or along with the CaMKII $\alpha($ T286D) construct at 14 DIV and imaged at 17 DIV. $\boldsymbol{A}$, Representative images of neurons (top) and dendrites (bottom). $\boldsymbol{B}$, Quantification for $\boldsymbol{A} ; n=15$ neurons for each group. Data are presented as mean $\pm \mathrm{SEM} ;{ }^{*} p<0.05,{ }^{* *} p<0.01$.

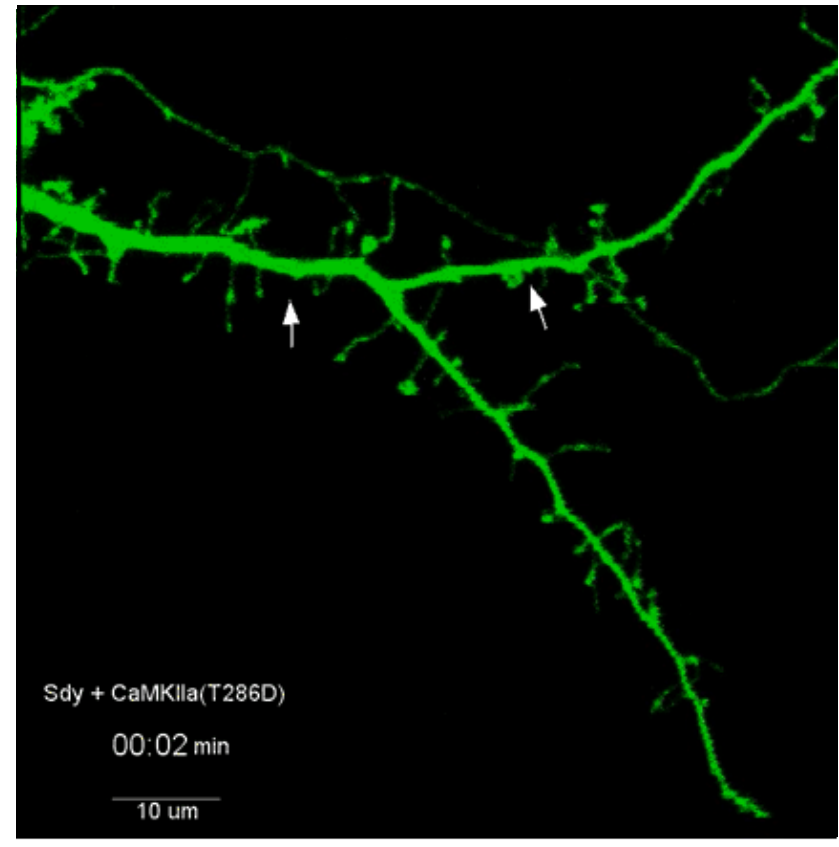

Movie 3. Dynamics of dendrite protrusions in sdy neurons. Hippocampal neurons from sdy mice were cotransfected with the Venus and the CaMKII $\alpha$ (T286D) constructs at 14 DIV. This movie shows confocal images of transfected dendrites taken every minute for 30 min at 17 DIV.

level of CaMKII $\alpha$ (a major isoform of CaMKII) is reduced in the prefrontal cortex (Papaleo et al., 2012), it was unchanged in the hippocampus (Fig. $3 A, B$ ). As CaMKII $\alpha$ is a synaptic protein, we also analyzed CaMKII $\alpha$ in the P2 fraction (crude synaptosomal fraction, enriched for presynaptic and postsynaptic proteins), and found that synaptic CaMKII $\alpha$ was deceased (Fig. 3A,B), likely due to fewer mushroom/thin spines (which accommodate mature synapses) in $s d y$ neurons. In addition, the active form of CaMKII $\alpha$ (phosphorylated at Thr286) was also reduced in both the whole-cell lysate and the $\mathrm{P} 2$ fraction of the $s d y$ hippocampus (Fig. $3 A, B$ ). These results indicate that the activity of CaMKII $\alpha$ is lower in the hippocampus of $s d y$ mice.

We next tested whether CaMKII $\alpha$ affects the dynamics of dendritic protrusions. We cotransfected cultured hippocampal neurons (wild-type, 14 DIV) with the Venus construct and siRNAs against CaMKII $\alpha$ (See Material and Methods) to knock down CaMKII $\alpha$, or a construct expressing constitutively active
CaMKII $\alpha$ (T286D, CA-CaMKII $\alpha$ ) to elevate CaMKII activity. At $17 \mathrm{DIV}$, neurons were imaged every $1 \mathrm{~min}$ for $30 \mathrm{~min}$. We detected more addition and retraction of dendritic protrusions, conversion of mushroom/thin spines to filopodia, and total dynamic events in CaMKII $\alpha$ siRNA transfected than in control cells (Fig. 3C-I). Transfection of CA-CaMKII $\alpha$ also increased the conversion of mushroom/thin spines to filopodia, but had no effect on other types of dynamic events (Fig. 3C-I), possibly due to abundant endogenous CaMKII in synapses (Andersen et al., 2007). Thus, the physiological level of CaMKII activity is required for the stabilization of mushroom/thin spines. Consistent with CaMKII $\alpha$ 's preferential effect on the transformation of mushroom/thin spines, while the densities of filopodia and stubby spines were intact in CA-CaMKII $\alpha$ or CaMKII $\alpha$ siRNAtransfected cells, that of mushroom/thin spines was increased in CA-CaMKII $\alpha$-transfected, but decreased in CaMKII $\alpha$ siRNAtransfected neurons (Fig. 4).

Together, these results indicate that $\mathrm{CaMKII} \alpha$ regulates the addition and retraction of dendritic protrusions and the stabilization of mushroom/thin spines.

\section{Decreased CaMKII $\alpha$ activity in $s d y$ mice contributes to the} hyperactivity of dendritic protrusions

Recognizing that CaMKII $\alpha$ regulates the dynamics of dendritic protrusions, and its activity is reduced in $s d y$ mice, we next investigated whether lower CaMKII $\alpha$ activity might be responsible for the excessive dynamics of dendritic protrusions in these mice. To test this possibility, we transfected cultured hippocampal neurons (14 DIV) prepared from $s d y$ mice with the CA-CaMKII $\alpha$ along with the Venus construct, and took time-lapse images at $3 \mathrm{~d}$ after transfection. Notably, transfection of CA-CaMKII $\alpha$ abolished changes to the dynamics of dendritic protrusions and the number of mushroom/thin spines in $s d y$ cells (Figs. 5-6; Movies $2,3)$. Together, these results indicate that the hyperactivity of dendritic protrusions in $s d y$ mice is caused, at least in part, by reduced CaMKII $\alpha$ activity.

\section{More CaMKII $\alpha$ binds to Abil in sdy mice}

Having found that CaMKII $\alpha$ plays an important role in the hyperdynamics of dendritic protrusions in $s d y$ mice, we proceeded to investigate why CaMKII $\alpha$ activity is lower in these mice. Activity-dependent modulation of Abi interactor 1 (Abi1) binds to and inhibits CaMKII $\alpha$ (Park et al., 2012). Abi1 also forms complexes with dysbindin-1 and the WASP family 
A

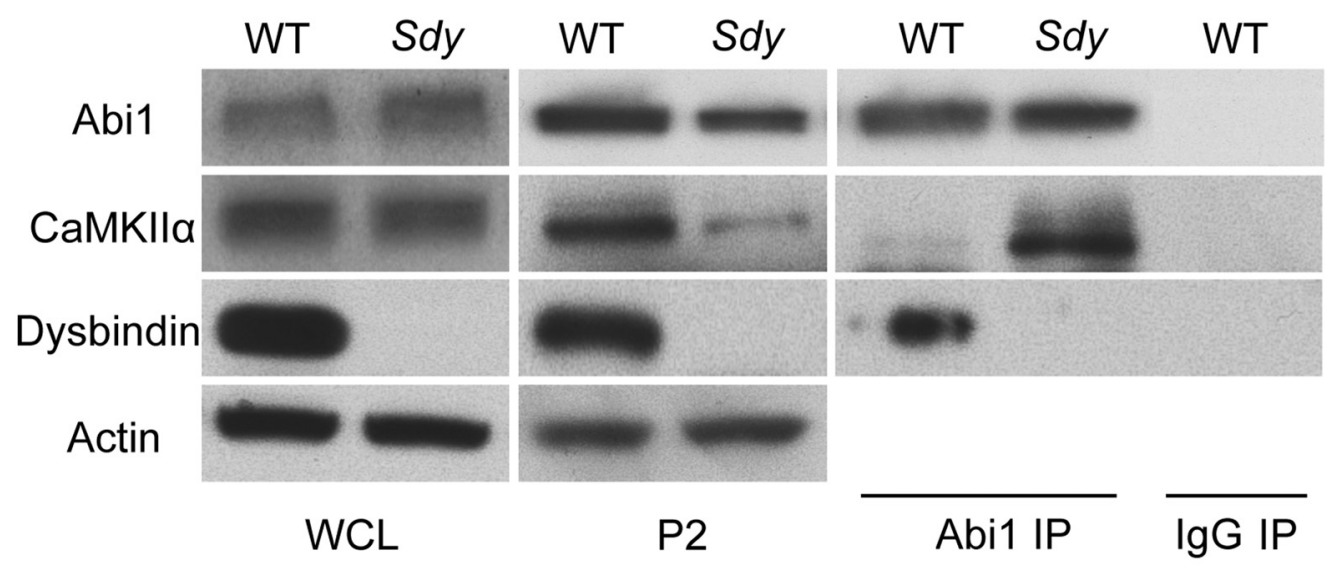

B

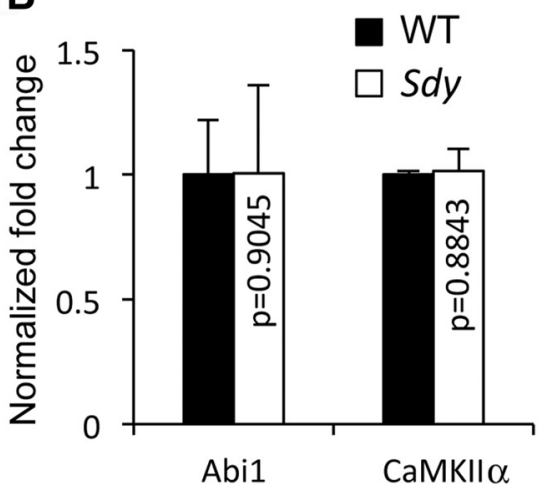

C

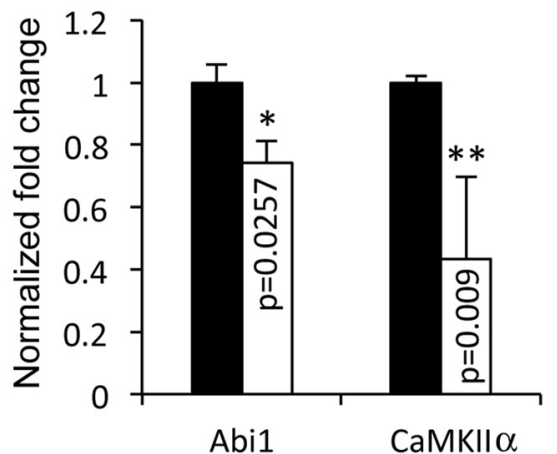

D

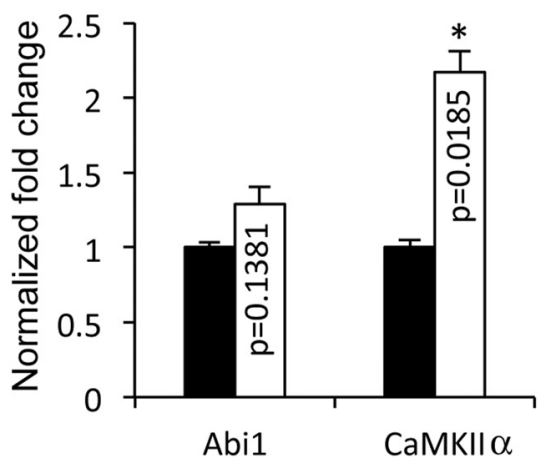

Figure 7. Abi1 forms more complexes with CaMKIl $\alpha$ in sdy mice. The hippocampal tissue removed from WT and sdy mice (3-week-old) was used for coimmunoprecipitation with an antibody against Abi1. $\boldsymbol{A}$, Representative immunoblots. $\boldsymbol{B}-\boldsymbol{D}$, Quantification of Abi1 and CaMK $\alpha$ in whole-cell lysates $(\boldsymbol{B})$, the P2 fraction $(\boldsymbol{C})$ and the immunoprecipitate $(\boldsymbol{D})$. Data represent the average of three independent experiments using three pairs of wild-type and sdy mice, and are presented as mean \pm SEM; ${ }^{*} p<0.05,{ }^{* *} p<0.01$.

verprolin homology isoform 2 (WAVE2; Ito et al., 2010). In $s d y$ mice, the lack of dysbindin can eliminate the Abi1/dysbindin complex, and therefore might result in more Abil/ CaMKII $\alpha$ complexes and inhibition of CaMKII $\alpha$. To test this possibility, we analyzed CaMKII $\alpha$ associated with Abil in $s d y$ and wild-type mice using coimmunoprecipitation with an antibody against Abil. We noticed that although the protein level of Abil in the whole-cell lysate was unchanged, it was decreased in the P2 fraction of $s d y$ hippocampus (Fig. 7), likely caused by the reduction of mushroom/thin spines. Even the $s d y$ hippocampus had less synaptic Abil, the Abil antibody pulled down more CaMKII $\alpha$ from the P2 fraction of $s d y$ than from that of wild-type hippocampi (Fig. 7). These results indicate that the interaction of CaMKII $\alpha$ and Abil is augmented in $s d y$ mice. Hence, lower CaMKII $\alpha$ activity in $s d y$ mice is caused, at least in part, by Abil-mediated inhibition.

\section{Abil contributes to the hyperdynamics of dendritic protrusions in $s d y$ mice}

In $s d y$ neurons, CA-CaMKII $\alpha$ can rescue the number of mushroom/thin spines, but has no effect on filopodium overgrowth (Figs. 5, 6). Hence, CaMKII-independent mechanisms may also contribute to $s d y$ mice's protrusion phenotype. Dysbindin binds to and facilitates the interaction of Abil and WAVE2 (a regulator of actin reorganization; Ito et al., 2010; Rotty et al., 2013). Knockdown of dysbindin causes a reduction in the formation of the Abi1/WAVE2 complex and presumably affects actin dynamics, a process important for the morphogenesis of dendritic protru- sions (Li and Sheng, 2003; Ito et al., 2010). In addition, we found that synaptic expression of Abil is reduced (Fig. 7) and it has been reported that Abil overexpression can restore the density and morphology of dendritic protrusions in dysbindin knockdown neurons (Ito et al., 2010). We therefore tested whether Abil also contributes to the changes in protrusion dynamics in $s d y$ mice.

We transfected primary hippocampal neurons prepared from $s d y$ mice with a construct expressing Abil, and took time-lapse images of transfected dendrites as described above. Abnormal protrusion dynamics in $s d y$ neurons including formation, retraction, and conversion between different types of protrusions were all normalized by transfection of the Abil construct (Fig. 8). The changes to the densities of mushroom/thin spines and filopodia in $s d y$ neurons were also obliterated by Abil overexpression (Fig. 9). As CaMKII $\alpha$ does not, whereas Abil can, rescue filopodium density in $s d y$ neurons, Abil can regulate dendritic protrusions through CaMKII $\alpha$-independent mechanisms, such as actin reorganization.

\section{Discussion}

In this study, we used time-lapse imaging to investigate the role of the schizophrenia risk gene dysbindin in the morphogenesis of dendritic spines. Our results show that dysbindin regulates the dynamics of dendritic protrusions. In $s d y$ mice, formation, retraction, and transformation of dendritic protrusions are more active. We also found that CaMKII $\alpha$ is required for the stabilization of dendritic protrusions, and that 
A

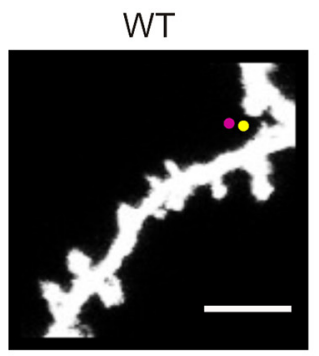

C

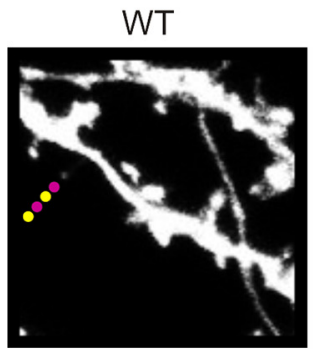

E

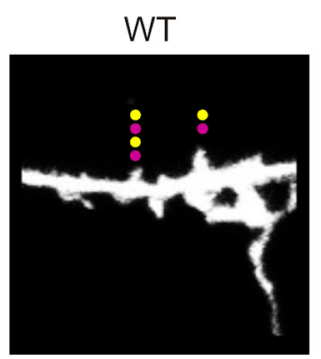

Sdy

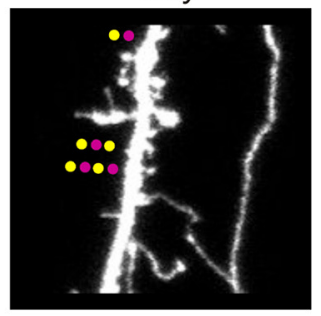

Sdy

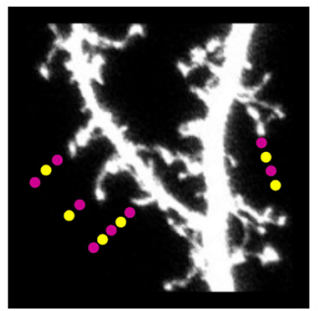

$S d y$

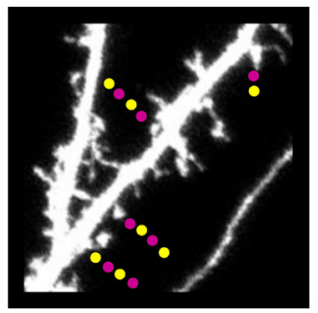

$S d y+A b i 1$

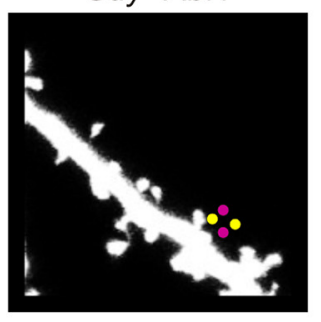

Sdy+Abi 1

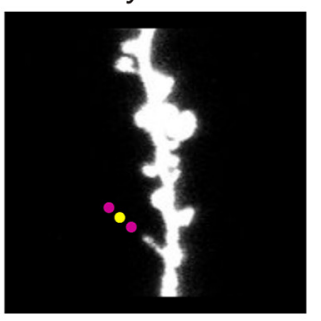

Sdy+Abi1

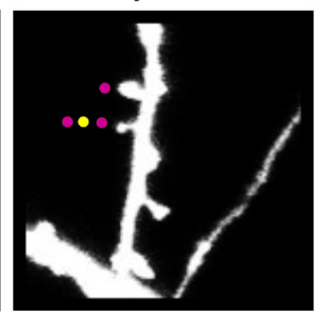

B

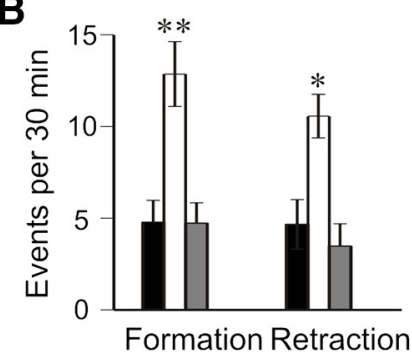

D

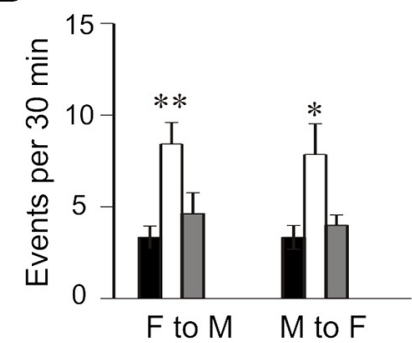

F

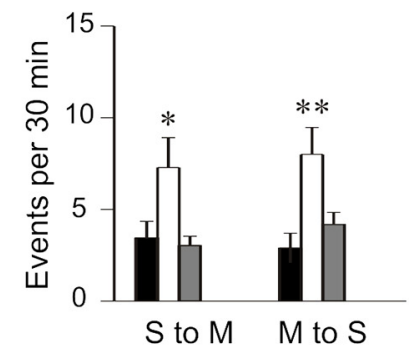

G

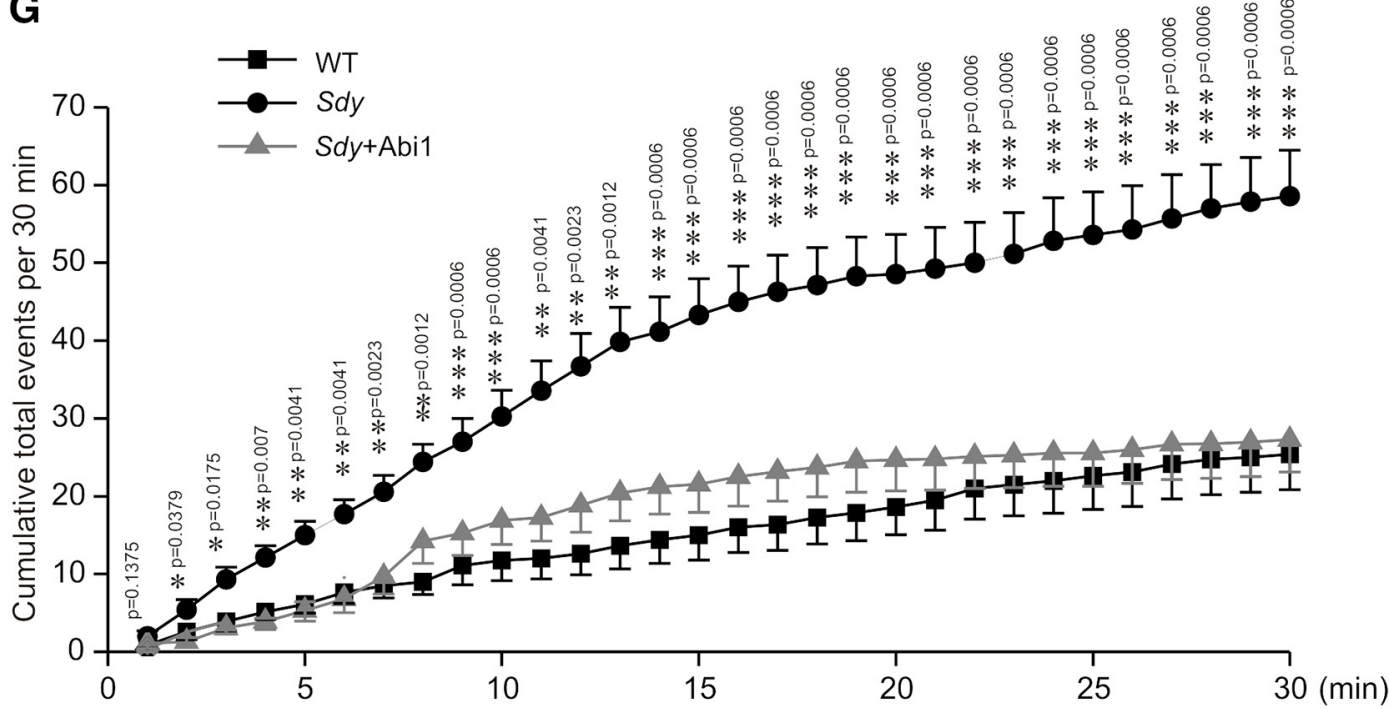

Figure 8. Abi1 eliminates protrusion hyperdynamics of sdy neurons. Hippocampal neurons from wild-type and sdy mice were transfected at $14 \mathrm{DIV}$ with the Venus construct alone or along with the Abi1 construct, and imaged every minute for $30 \mathrm{~min}$ at 17 DIV. $\boldsymbol{A}, \boldsymbol{C}, \boldsymbol{E}$, Representative images superimposed from those taken at four contiguous time points during the 30 min live-imaging period. Red dots represent protrusion retraction $(\boldsymbol{A})$, the transformation from mushroom/thin spines to filopodia $(\boldsymbol{C})$, the conversion from mushroom/thin to stubby spines $(\boldsymbol{E})$; yellow dots indicate protrusion addition $(\boldsymbol{A})$, the transformation from filopodia to mushroom/thin spines $(\boldsymbol{C})$, the conversion from stubby to mushroom/thin spines $(\boldsymbol{E})$. $\boldsymbol{B}, \boldsymbol{D}, \boldsymbol{F}, \mathrm{Quantification}$ of $\boldsymbol{A}, \boldsymbol{C}, \boldsymbol{E}$. $\boldsymbol{G}, \mathbf{C}$ umulative frequency plot for the total number of all types of dynamic events taking place during the 30 min period. Scale bar, $5 \mu \mathrm{m}$. Data are presented as mean \pm SEM; ${ }^{*} p<0.05,{ }^{* *} p<0.01,{ }^{* *} p<0.001$. 
A
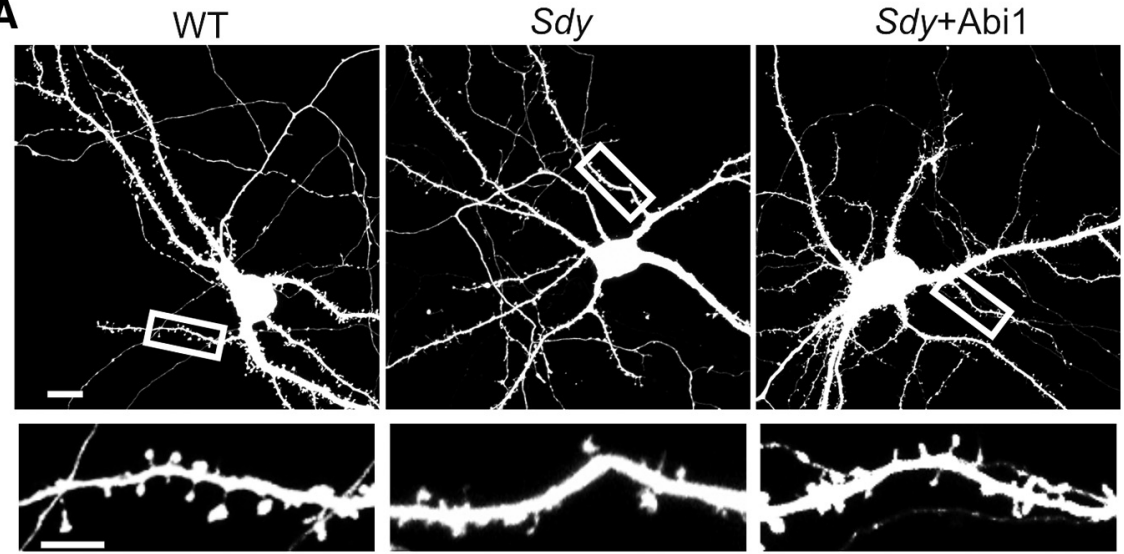

B

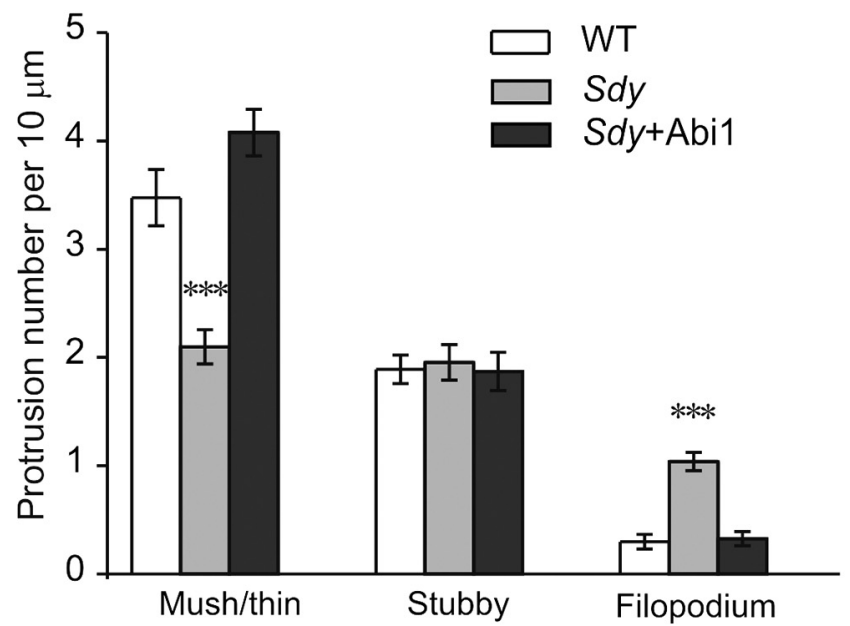

Figure 9. Abi1 restores the densities of mushroom/thin spines and filopodia in sdy neurons. Cultured hippocampal neurons from sdy or wild-type mice were transfected with the Venus construct alone or along with the Abi1 construct at 14 DIV and imaged at 17 DIV. $\boldsymbol{A}$, Representative images of neurons (top) and dendrites (bottom). $\boldsymbol{B}$, Quantification for $\boldsymbol{A} ; n=15$ neurons for each group. Data are presented as mean \pm SEM; ${ }^{* * *} p<0.001$.

reduced CaMKII $\alpha$ activity in $s d y$ mice contributes to the hyperactivity of protrusions.

Because genetic variants of the $d y$ sbindin gene are associated with risks of schizophrenia, there is a keen interest in the biology of dysbindin. Using sdy mice and dysbindin siRNAs, several groups including us show that dysbindin is required for spine development. The specific stage of spine development that is regulated by dysbindin, however, has yet to be elucidated. Our findings of excessive addition, retraction, and transformation of dendritic protrusions in $s d y$ neurons suggest that dendritic protrusions and synaptic connections formed on them are highly unstable in these cells. Destabilization of protrusions can hamper their maturation. Indeed, consistent with previous reports (Jia et al., 2013), we found that the number of mature spines (mushroom and thin spines) is reduced in $s d y$ neurons. It is possible that the dysbindin gene contributes to the synaptopathology of schizophrenia by destabilizing dendritic spines during neuronal development.

How does dysbindin regulate spine dynamics? A few lines of evidence from our study suggest that CaMKII is a mediator for the regulation of spine dynamics by dysbindin. First, phosphorylated CaMKII $\alpha$ (the active form of CaMKII $\alpha$ ) is decreased in the hippocampus of $s d y$ mice due to excessive formation of the Abil/ CaMKII $\alpha$ complexes. Second, the CaMKII $\alpha$ siRNA enhances protrusion dynamics, indicating that CaMKII activity is required to stabilize dendritic protrusions. This finding is consistent with a previous one from the barrel cortex of mice that CaMKII activity is required for whisker trimming-induced stabilization of new spines (Wilbrecht et al., 2010). Hence, CaMKII is essential for spine stabilization in both development and experience-dependent plasticity of spines. Last and perhaps more importantly, constitutively active CaMKII $\alpha$ restores protrusion stability in $s d y$ mice.

We found that, likely due to CaMKII's stabilizing effect on spines, expression of constitutively active CaMKII $\alpha$ increases the number of mushroom/thin spines. By contrast, the number of stubby spines is not changed by constitutively active CaMKII $\alpha$. The different responses of stubby and mushroom/thin spines to CaMKII overactivation could be due to the tendency of stabilized stubby spines to turn into mushroom/thin spines (which predominate in mature neurons), or perhaps to a high sensitivity CaMKII activity that would allow even small endogenous amounts of CaMKII to have already elicited stubby spines' maximal response.

It should be noted that knockdown of CaMKII $\alpha$ only increases the conversion of mushroom/thin spines to filopodia, whereas transfection of CA-CaMKII $\alpha$ corrects all abnormal spine dynamics in $s d y$ neurons. These findings suggest that multiple factors in addition to CaMKII $\alpha$ (some of which have overlapping function with $\mathrm{CaMKII} \alpha$ ) contribute to the protrusion phenotype of $s d y$ mice. Our data show that one such factor is Abil. By binding to CaMKII $\alpha$, Abil causes a decrease in CaMKII $\alpha$ activity and consequent changes to the dynamics and number of dendritic protrusions in $s d y$ mice. In addition, Abil also modulates protrusions through CaMKII $\alpha$-independent pathways, as Abil overexpression in $s d y$ neurons abolishes filopodium overgrowth, a phenotype unchanged by expression of constitutively active $\mathrm{CaMKII} \alpha$. The multifaceted mechanisms used by Abil to regulate protrusions is conferred by its diverse binding partners including CaMKII $\alpha$ (stabilizing dendritic protrusions) and WAVE2 (which activates actin-related proteins 2 and 3 to regulate actin dynamics; Rotty et al., 2013).

CaMKII is essential for cognitive functions. Mice with reduced CaMKII $\alpha$ expression exhibit behavioral abnormalities including deficits in working memory which is an endophenotype of schizophrenia (Yamasaki et al., 2008). Our findings of CaMKII's role in abnormal protrusion dynamics of $s d y$ neurons suggest that the behavioral impairment of these mice may in part stem from the "miswiring" of neural circuits resulting from the destabilization of dendritic protrusions during brain development.

In summary, by examining the dynamic morphogenesis of dendritic protrusions using time-lapse imaging, we demonstrate that dysbindin and CaMKII are key regulators involved in the 
stabilization of dendritic protrusions. Our findings also suggest that reduced dysbindin expression might contribute to the synaptopathology of schizophrenia by destabilizing dendritic protrusions and synaptic connections on them.

\section{References}

Andersen P, Morris R, Amaral D, Bliss T, O'Keefe J (2007) The hippocampus book. New York: Oxford UP.

Benson MA, Newey SE, Martin-Rendon E, Hawkes R, Blake DJ (2001) Dysbindin, a novel coiled-coil-containing protein that interacts with the dystrobrevins in muscle and brain. J Biol Chem 276:24232-24241. CrossRef Medline

Garey LJ, Ong WY, Patel TS, Kanani M, Davis A, Mortimer AM, Barnes TR, Hirsch SR (1998) Reduced dendritic spine density on cerebral cortical pyramidal neurons in schizophrenia. J Neurol Neurosurg Psychiatry 65: 446-453. CrossRef Medline

Glantz LA, Lewis DA (2000) Decreased dendritic spine density on prefrontal cortical pyramidal neurons in schizophrenia. Arch Gen Psychiatry 57:65-73. CrossRef Medline

Howes OD, Kapur S (2009) The dopamine hypothesis of schizophrenia: version III-the final common pathway. Schizophr Bull 35:549-562. CrossRef Medline

Ito H, Morishita R, Shinoda T, Iwamoto I, Sudo K, Okamoto K, Nagata K (2010) Dysbindin-1, WAVE2 and Abi-1 form a complex that regulates dendritic spine formation. Mol Psychiatry 15:976-986. CrossRef Medline

Jia JM, Zhao J, Hu Z, Lindberg D, Li Z (2013) Age-dependent regulation of synaptic connections by dopamine D2 receptors. Nat Neurosci 16:16271636. CrossRef Medline

Ji Y, Yang F, Papaleo F, Wang HX, Gao WJ, Weinberger DR, Lu B (2009) Role of dysbindin in dopamine receptor trafficking and cortical GABA function. Proc Natl Acad Sci U S A 106:19593-19598. CrossRef Medline

Kolluri N, Sun Z, Sampson AR, Lewis DA (2005) Lamina-specific reductions in dendritic spine density in the prefrontal cortex of subjects with schizophrenia. Am J Psychiatry 162:1200-1202. CrossRef Medline

Kolomeets NS, Orlovskaya DD, Rachmanova VI, Uranova NA (2005) Ultrastructural alterations in hippocampal mossy fiber synapses in schizophrenia: a postmortem morphometric study. Synapse 57:47-55. CrossRef Medline

Lau LF, Mammen A, Ehlers MD, Kindler S, Chung WJ, Garner CC, Huganir RL (1996) Interaction of the $N$-methyl-D-aspartate receptor complex with a novel synapse-associated protein, SAP102. J Biol Chem 271:2162221628. CrossRef Medline

Li W, Zhang Q, Oiso N, Novak EK, Gautam R, O’Brien EP, Tinsley CL, Blake DJ, Spritz RA, Copeland NG, Jenkins NA, Amato D, Roe BA, Starcevic M, Dell'Angelica EC, Elliott RW, Mishra V, Kingsmore SF, Paylor RE, Swank RT (2003) Hermansky-Pudlak syndrome type 7 (HPS-7) results from mutant dysbindin, a member of the biogenesis of lysosome-related organelles complex 1 (BLOC-1). Nat Genet 35:84-89. CrossRef Medline
Li Z, Sheng M (2003) Some assembly required: the development of neuronal synapses. Nat Rev Mol Cell Biol 4:833-841. CrossRef Medline

Lynall ME, Bassett DS, Kerwin R, McKenna PJ, Kitzbichler M, Muller U, Bullmore E (2010) Functional connectivity and brain networks in schizophrenia. J Neurosci 30:9477-9487. CrossRef Medline

Nagai T, Ibata K, Park ES, Kubota M, Mikoshiba K, Miyawaki A (2002) A variant of yellow fluorescent protein with fast and efficient maturation for cell-biological applications. Nat Biotechnol 20:87-90. CrossRef Medline

Papaleo F, Yang F, Garcia S, Chen J, Lu B, Crawley JN, Weinberger DR (2012) Dysbindin-1 modulates prefrontal cortical activity and schizophrenia-like behaviors via dopamine/D2 pathways. Mol Psychiatry 17:85-98. CrossRef Medline

Park E, Chi S, Park D (2012) Activity-dependent modulation of the interaction between CaMKIIalpha and Abil and its involvement in spine maturation. J Neurosci 32:13177-13188. CrossRef Medline

Parnass Z, Tashiro A, Yuste R (2000) Analysis of spine morphological plasticity in developing hippocampal pyramidal neurons. Hippocampus 10: 561-568. CrossRef Medline

Rotty JD, Wu C, Bear JE (2013) New insights into the regulation and cellular functions of the ARP2/3 complex. Nat Rev Mol Cell Biol 14:7-12. CrossRef Medline

Straub RE, Jiang Y, MacLean CJ, Ma Y, Webb BT, Myakishev MV, HarrisKerr C, Wormley B, Sadek H, Kadambi B, Cesare AJ, Gibberman A, Wang X, O'Neill FA, Walsh D, Kendler KS (2002) Genetic variation in the 6 p22.3 gene DTNBP1, the human ortholog of the mouse dysbindin gene, is associated with schizophrenia. Am J Hum Genet 71:337-348. CrossRef Medline

Talbot K, Eidem WL, Tinsley CL, Benson MA, Thompson EW, Smith RJ, Hahn CG, Siegel SJ, Trojanowski JQ, Gur RE, Blake DJ, Arnold SE (2004) Dysbindin-1 is reduced in intrinsic, glutamatergic terminals of the hippocampal formation in schizophrenia. J Clin Invest 113:1353-1363. CrossRef Medline

Weickert CS, Rothmond DA, Hyde TM, Kleinman JE, Straub RE (2008) Reduced DTNBP1 (dysbindin-1) mRNA in the hippocampal formation of schizophrenia patients. Schizophr Res 98:105-110. CrossRef Medline

Wenzel J, Bogolepov NN (1976) Electronmicroscopical and morphometrical study of rat hippocampal synapses (in German). J Hirnforsch 17:399448. Medline

Wilbrecht L, Holtmaat A, Wright N, Fox K, Svoboda K (2010) Structural plasticity underlies experience-dependent functional plasticity of cortical circuits. J Neurosci 30:4927-4932. CrossRef Medline

Yamasaki N, Maekawa M, Kobayashi K, Kajii Y, Maeda J, Soma M, Takao K, Tanda K, Ohira K, Toyama K, Kanzaki K, Fukunaga K, Sudo Y, Ichinose H, Ikeda M, Iwata N, Ozaki N, Suzuki H, Higuchi M, Suhara T, et al. (2008) Alpha-CaMKII deficiency causes immature dentate gyrus, a novel candidate endophenotype of psychiatric disorders. Mol Brain 1:6. CrossRef Medline 